\title{
Synthesis of PANI@ZnO Hybrid Material and Evaluations in Adsorption of Congo Red and Methylene Blue Dyes: Structural Characterization and Adsorption Performance
}

Imane Toumi

Abdelhamid Ibn Badis University of Mostaganem

Halima Djelad

Abdelhamid Ibn Badis University of Mostaganem

Faiza Chouli

Abdelhamid Ibn Badis University of Mostaganem

Benyoucef Abdelghani ( $\sim$ abdelghani@ua.es)

Faculté des Sciences et Thechnologie https://orcid.org/0000-0002-0247-2808

\section{Research Article}

Keywords: PANI, ZnO, Nanocomposite, Congo Red, Methylene Blue, Removal

Posted Date: June 30th, 2021

DOl: https://doi.org/10.21203/rs.3.rs-661310/v1

License: (c) (i) This work is licensed under a Creative Commons Attribution 4.0 International License. Read Full License

Version of Record: A version of this preprint was published at Journal of Inorganic and Organometallic Polymers and Materials on August 7th, 2021. See the published version at https://doi.org/10.1007/s10904-021-02084-0. 
$1 \quad$ Synthesis of PANI@ZnO hybrid material and evaluations in adsorption of

2

3

4

5

6

7

8

9

10

11

12

13

14

15

16

17 10

adsorption performance

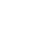

I. Toumi ${ }^{1}$, H. Djelad ${ }^{2,3}$, F. Chouli $^{1}$, A. Benyoucef ${ }^{2 *}$

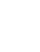

${ }^{1}$ Faculty of Science and Technology; Abdelhamid Ibn Badis University of Mostaganem. Algeria

${ }^{2}$ LMAE Laboratory; University of Mustapha Stambouli Mascara, Algeria

${ }^{3}$ University Materials Institute of Alicante (IUMA); University of Alicante, Spain

2 *Corresponding author : abdelghani@ua.es or a.benyoucel@univ-mascara.dz 


\section{Abstract}

In this research, a simple oxidation chemical process was applied for the synthesis of novel PANI@ZnO nanocomposite. The prepared nanocomposites were characterized by XPS, XRD, FTIR, SEM, TGA and $\mathrm{N}_{2}$ adsorption-desorption isotherms. Thereby, PANI@ZnO highest $\mathrm{S}_{\mathrm{BET}}$ values (about $40.84 \mathrm{~m}^{2} \cdot \mathrm{g}^{-1}$ ), total mesoporous volume (about $3.214 \mathrm{~cm}^{3} \cdot \mathrm{g}^{-1}$ ) and average pore size (about $46.12 \mathrm{~nm}$ ). Afterwards, the prepared nanomaterial was applied as novel nanoadsorbent for the adsorption of Congo Red (CR) and Methylene Blue (MB) dyes from aqueous solutions at $298 \mathrm{~K}$ and $\mathrm{pH}$ 5.0. Besides, the pseudo-second-order model was obtained the best for the adsorption of both dyes. In the case of isotherm models, the Freundlich model showed the best fit. After removal, the spent adsorbent was regenerated. With the regeneration repeated five cycles, the PANI@ZnO regeneration efficiency remained at a very adequate level.

Keywords: PANI; ZnO; Nanocomposite; Congo Red; Methylene Blue; Removal. 


\section{Introduction}

Dye effluents are one of the most dangerous chemical product classes found in industrial textile waste to the environment. These dyes can cause dermatitis, allergy and too provoke cancer [1-3]. Therefore, its elimination from different aqueous wastes is required and necessary to protect environment and human health. Generally, membrane filtration process, precipitation, coagulation, biological treatment, precipitation, adsorption, ion exchange, electrochemical process, photocatalytic degradation and ozonation are adequate candidates for such purpose [4-11]. In addition, adsorption treatment is the most effective method because providing the simplicity in employment, flexibility and low cost [12].

Similarly to conducting polymer, polyaniline (PANI) is a popular. This conductive product also has other appealing features such as good environmental stability, simple synthesis, ability to dope with protonic acids, and the being of amine groups in its structure and higher electrical conductivity [13-15]. The polyaniline has been prepared via chemical oxidative polymerization and electropolymerization process [16-19]. Generally, the usage of PANI is presently limited, due to its poor mechanical property. The PANI nanocomposites with different inorganic materials greatly ameliorate their physical and structural properties for pertinent applications [20-22]. Among the inorganic nanomaterials, $\mathrm{ZnO}$ nanoparticles have received vast interest in exclusive electrical, photocatalytic, adsorption, electronic and optical properties due to their wide bandgap $(3.31 \mathrm{eV})$ as well as their low cost [23, 24]. Several synthesis methods have been widely used for the synthesis of the hybrid materials of PANI with $\mathrm{ZnO}$ [17]. Additionally, PANI@inorganic hybrid is already an established adsorbent of organic pollutants in aqueous solution, such as Orange G, Methyl orange, Methylene blue, Malachite green, Congo red, Amido black 10B [25-29], etc. 

in-situ chemical oxidative process. The adsorbent product was characterized by different techniques XPS, XRD, FT-IR, SEM, TGA and BET. The removal of Congo red (CR) and Methylene blue (MB) using PANI@ZnO adsorbent was studied. The process of adsorption was established through the kinetics, isotherm and regeneration results.

\section{Experimental}

\subsection{Materials}

Congo red (CR) and Methylene blue (MB), Aniline (ANI), Ammonium persulfate (APS), Zinc oxide $\mathrm{ZnO}$ (> 99\%), Hydrochloric acid 37\% and Ethanol $96 \%$ made by Merck Company. Deionized $\mathrm{H}_{2} \mathrm{O}$ was used for all experiments.

\subsection{Measurements}

FTIR Spectrometer (Bruker-Inc., Model-Alpha spectrophotometer) was applied to determine the functional groups. XRD (Bruker-CCD Apex instrument) was applied to determine the structural properties of samples. Calculation of the specific surface area was performed by $\mathrm{N}_{2}$ adsorption \& desorption analysis (Autosorb-6-Quantachrome equipment). UV-Spectrophotometer (Hitachi U-3000 Spectrophotometer) was applied to measure the MO concentration. (SEM) images of the products were taken using (FEI Quanta 400 FEG). Thermogravimetry Analyze (TGA) (Hitachi STA7200 Instrument) was used to determine the thermal and/or oxidative stabilities of materials as well as their. X-ray photoelectron spectroscopy analysis (XPS) was controlled by (VG Microtech Multilab 3000-electron) spectrometer. [20, 30].

\subsubsection{Porous texture characterization}


The microscopic pore structure property of adsorbent was characterized by physical adsorption of gases (nitrogen at 77K \& Carbon dioxide at 273K) using Micromeritics ASAP$2020 \mathrm{M}$ system. Correspondingly, $\mathrm{N}_{2}$ adsorption is mainly to gain the information on total micropores volume ( $\left.\mathrm{V}_{\mathrm{DR}}\right)$ applying the Dubinin-Radushkevich (DR) formula and to determine the specific surface area according to the BET law $\left(\mathrm{S}_{\mathrm{BET}}\right)[25,31]$.

\subsection{Synthesis of adsorbent material}

Adsorbent material was synthetized by insitu polymerization of ANI $220 \mathrm{~mol}$ in $\mathrm{HCl}$ dispersions of $\mathrm{ZnO}$ nanoparticles. $1.0 \mathrm{~g}$ of $\mathrm{ZnO}$ was added to a $0.5 \mathrm{M} \mathrm{HCl}$ and sonicated using probe ultrasound for $30 \mathrm{~min}$. Thereafter, the ANI was added, and the solution was sonicated also $30 \mathrm{~min}$ to prepare stable suspension. Finally, APS dissolved in $0.5 \mathrm{M}$ of $\mathrm{HCl}$ was added dropwise to solution of ANI with $\mathrm{ZnO}$ under constant stirring (the molar ratio of ANI to APS was 1:1). The preparation was carried out at $298 \mathrm{~K}$ for $24 \mathrm{~h}$. The final produced were filtered, washed with deionized $\mathrm{H}_{2} \mathrm{O}$ and then dried in oven at $333 \mathrm{~K}$ for $24 \mathrm{~h}$ [20, 30-32]. The PANI was synthetized in similar way mentioned above but in absence of $\mathrm{ZnO}$.

\subsection{Adsorption tests}

The 1000ppm stock dyes (CR or MB) solution was synthesized through dissolving $1.0 \mathrm{~g}$ of $\mathrm{CR}$ powder in $1 \mathrm{~L}$ of deionized $\mathrm{H}_{2} \mathrm{O}$. Then, through dilution, the solution was synthesized with the required initial concentrations of dyes from 5 to $200 \mathrm{ppm}$.

\subsubsection{Batch adsorption experiments}

Kinetics of batch adsorption experiments were considered to investigate the time to reach equilibrium and carried out at dyes $(\mathrm{CR}$ or $\mathrm{MB})$ solution concentrations of $5 \mathrm{ppm}, 10 \mathrm{ppm}$, 50ppm, 100ppm, 150ppm and 200ppm with $10 \mathrm{mg}$ of the PANI@ZnO adsorbent in the ambient temperature. The $\mathrm{CR}$ and $\mathrm{MB}$ solution concentration was identifying by $\mathrm{UV}-\mathrm{Vis}$ 
spectrophotometer in wavelength of maximum absorbance of $497 \mathrm{~nm}$ and $664 \mathrm{~nm}$, respectively.

A calibration curve of concentration-vs-absorbance was determined by Beer-Lambert's equation. The quantity of dyes adsorbed at equilibrium, $Q_{e q}\left(\mathrm{mg}_{\mathrm{g}} \mathrm{g}^{-1}\right)$, was established applied formula below:

$$
Q_{e q}=\frac{\left(C_{0}-C_{e q}\right) V}{m}
$$

113 Here, $m(\mathrm{~g})$ is the amount of adsorbent; $C_{0}$ and $C_{e q}\left(\mathrm{mg} \cdot \mathrm{L}^{-1}\right)$ are the initial and equilibrium 114 concentrations of dye, respectively; $\mathrm{V}(\mathrm{mL})$ is dye volume; $Q_{e q}\left(\mathrm{mg} . \mathrm{g}^{-1}\right)$ is the quantity of dye 115 adsorbed by adsorbent at time $t$. The needful properties of the Langmuir model can be proved in terms of a dimensionless separation factor $\left(R_{L}\right)$ are obtained by the following:

$$
R_{L}=\frac{1}{1+K_{L} C_{0}}
$$

119 Here, $C_{0}$ : the dye concentration at equilibrium $\left(\mathrm{mg} \cdot \mathrm{L}^{-1}\right)$ and $K_{L}$ : the Langmuir constant 120 (L.mg $\left.{ }^{-1}\right) \cdot R_{L}$ shows the state of isotherm to be either unfavorable for $R_{L}>1$, favorable $\left(0<R_{L}<\right.$ 1), linear for $R_{L}=1$ or irreversible for $R_{L}=0$ [33]. In conformity with the Freundlich isotherm, the adsorbed molecules cannot be greater than of active sites number, and the layer formed on nanoadsorbent surface authorized development of following layers [34]. The isotherm is determined by the next law:

$$
\log Q_{e q}=\log K_{F}+\frac{1}{n} \log C_{e q}
$$


Here, $K_{F}:$ Freundlich-constant $\left(\mathrm{L}^{\mathrm{mg}}{ }^{-1}\right) ; 1 / n$ : intensity of adsorption constant ; $Q_{e q}$ : adsorption capacity of dye adsorbed at equilibrium $\left(\mathrm{mg} \cdot \mathrm{g}^{-1}\right)$ and $C_{e q}$ : equilibrium concentration of dye (mg. $\left.\mathrm{L}^{-1}\right)$.

Adsorption kinetic isotherms were used to describe adsorptive molecules transfer behavior and investigate factors affecting reaction rate. In the current work, pseudo first order (PFO) and pseudo second order (PSO) kinetics models were applied to research the batch adsorption performance.

PFO:

$$
\log \left(Q_{e q}-Q_{t}=\log Q_{e q}-\frac{k_{l}}{2.303}\right.
$$

PSO:

Here, $Q_{e q}$ is quantity of dye adsorbed $\left({\mathrm{mg} . \mathrm{g}^{-1}}^{-1}\right) Q_{t}$ is dye quantity on adsorbent surface at every time $t\left(\mathrm{mg} \mathrm{g}^{-1}\right)$ and $k$ is equilibrium speed-constant of the PFO.

\subsubsection{Adsorbent regeneration test}

From the operational perspective and environmental goals, adsorbent regeneration and reuse constitute one of the important and innovative aspects of economic feasibility. To investigate PANI@ZnO adsorbent regeneration performance, $0.1 \mathrm{~g}$ of the prepared adsorbent was poured in $25 \mathrm{ml}$ of dye (CR or MB) solution with a concentration of $150 \mathrm{ppm}$ at $298 \mathrm{~K}$ under stirring for $2 \mathrm{~h}$. The residue dye solution concentration was determined by UV-Vis spectrophotometer and dye adsorption capacity by PANI@ZnO was investigated. 
After that, the adsorbent was removed from the solution and placed in $40 \mathrm{ml}$ of nitric

acid 0.05 molar as elution solvent on a stirrer for 10 minutes. Afterwards, the PANI@ZnO adsorbent was washed with deionization $\mathrm{H}_{2} \mathrm{O}$ and placed in dye solution with the same condition and these stages were repeated for 5 cycles.

\section{Results and Discussion}

\subsection{Adsorbent characterization}

To further characterize micromorphology and molecular structure of the products, XPS, XRD, FITR, TGA, SEM and BET measurements were carried out. Fig. 1-a show the XPS wide survey-spectra of the $\mathrm{ZnO}$ sample give the characteristic peaks of $\mathrm{Zn3d}, \mathrm{Zn3p}, \mathrm{Zn3s}, \mathrm{C} 1 \mathrm{~s}$, $\mathrm{O} 1 \mathrm{~s}, \mathrm{Zn} 2 \mathrm{p} 3$ and Zn2p1 with the corresponding binding energies of $21.41 \mathrm{eV}, 72.94 \mathrm{eV}, 141.57$ $\mathrm{eV}, 285.57 \mathrm{eV}, 532.22 \mathrm{eV}, 1021.35 \mathrm{eV}$ and $1044.83 \mathrm{eV}$, respectively [35]. As demonstrated in Table 1, the high resolution XPS spectrum of Zn2p3 presented shows three evident signals located at $1021.69 \mathrm{eV}, 1022.45 \mathrm{eV}$ and $1023.62 \mathrm{eV}$ are arising from the $\mathrm{Zn}$ metal, $\mathrm{Zn}-\mathrm{O}$ and $\mathrm{Zn}(\mathrm{OH})_{2}$, respectively. Moreover, the XPS spectrum of PANI shows the C1s, N1s and O1s. On the one hand, analysis of the high-resolution N1s spectra using a peak of deconvolution (Table 1), revealed two functional groups around $399.70 \mathrm{eV}(=\mathrm{N}-)$ and $400.74 \mathrm{eV}(-\mathrm{NH}-)$. Furthermore, the $\mathrm{C} 1 \mathrm{~s}$ spectrum contained three contributions at $284.60 \mathrm{eV}(\mathrm{C}-\mathrm{H}, \mathrm{C}-\mathrm{C}$ or $\mathrm{C}=\mathrm{C})$, $285.92 \mathrm{eV}(\mathrm{C}-\mathrm{O} / \mathrm{C}-\mathrm{N})$ and $287.22 \mathrm{eV}(\mathrm{N}-\mathrm{C}=\mathrm{N})$. These assignments of the mentioned functional groups are in agreement with the literature [21]. Likewise, the XPS spectra confirm that $\mathrm{Zn}$ and $\mathrm{N}$ elements exists mainly in the form PANI@ $\mathrm{ZnO}$ surfaces, this indicating to successful formation of hybrid materials 
Fig. 1-b. display the FT-IR spectrum of synthesized PANI, it can be seen a series of characteristic peaks including $\mathrm{C}=\mathrm{C}$ stretching vibration of benzenoid units at $1500 \mathrm{~cm}^{-1}$ and $1589 \mathrm{~cm}^{-1}$ of PANI are presented [20, 21], which makes clear that the PANI is in semioxidation state. The band at $1239 \mathrm{~cm}^{-1}$ is attributed to $\mathrm{C}-\mathrm{N}$ stretching vibration of secondary aromatic amino structures [36]. The main characteristic band at $750 \mathrm{~cm}^{-1}$ is belonging to the aromatic $\mathrm{N}-\mathrm{H}$ stretching vibration of secondary aromatic amine bending vibration. Moreover, the main band at $1111 \mathrm{~cm}^{-1}$ is attributed to the out-of-plane bending vibration of $\mathrm{C}-\mathrm{H}$ within the stretching vibration of $\mathrm{C}-\mathrm{N}$ of the secondary aromatic amine structures bending vibration. Besides, the $\mathrm{ZnO}$ nanoparticles display one maximum at $537 \mathrm{~cm}^{-1}[37,38]$. Additional absorption bands were attributed to organic impurities originating from reaction intermediates, whilst one at $3438 \mathrm{~cm}^{-1}$ was ascribed to the $\mathrm{OH}$-group on $\mathrm{ZnO}$ surface. Moreover, the FTIR spectra of PANI@ZnO are which fully match PANI spectra. Therefore, the bands at 1602 and $1500 \mathrm{~cm}^{-1}$ are ascribed to vibrations of quinoid \& benzene rings, respectively. The other characteristic bands at 1302, 1104, 792 and $697 \mathrm{~cm}^{-1}$ can be attributed with the $\mathrm{C}-\mathrm{N}$ stretching of the secondary aromatic amine, aromatic $\mathrm{C}-\mathrm{H}$ in-plane and out-of-plane bending, respectively. Furthermore, the band of $\mathrm{ZnO}$ at $537 \mathrm{~cm}^{-1}$ are shifted to $569 \mathrm{~cm}^{-1}$, indicating the formation of PANI@ZnO hybrid. Generally, this results show a clear shifting of wavenumbers indicating the interaction between PANI and the surface of the $\mathrm{ZnO}$

The XRD patterns of the PANI, ZnO and PANI@ZnO samples, respectively (Fig. 1-c). The $\mathrm{ZnO}$ shows peaks at $2 \theta=31.78^{\circ}, 34.38^{\circ}, 36.24^{\circ}, 47.53^{\circ}, 56.63^{\circ}, 62.87^{\circ}$ and $67.91^{\circ}$ belong to (100), (002), (101), (102), (110), (103) and (112) crystal planes according to JCPSD card no. 01-007-2551. Moreover, the PANI, being semi crystalline in nature, showed two sharp bands centered at $2 \theta=7.43^{\circ}$ and $24.17^{\circ}$ corresponding to (002) and (200) crystal planes, with and a 
191

192

broad band indicating that the majority of PANI chains were oriented in these crystal planes. Also, broad a peak are observed between $2 \theta=13.18^{\circ}$ to $18.28^{\circ}$ indexed to $(011)$ and $(020)$. On the other hand, PANI@ $\mathrm{ZnO}$ shows two peaks at $2 \theta=31.81^{\circ}$ and $36.24^{\circ}$ corresponding to the reflections due to the $\mathrm{ZnO}(100)$ and (101) planes. The peak at $2 \theta=7.78^{\circ}$ of hybrid material also coincided with the (002) peak of pure PANI, but in contrast to PANI, the XRD peak of PANI@ZnO converted to a broad amorphous peak that is observed between $2 \theta=15.54^{\circ}$ to $30.53^{\circ}$. By comparing the $\mathrm{XRD}$ patterns of the hybrid adsorbent and $\mathrm{ZnO}$, it is assured that $\mathrm{ZnO}$ nanoparticles has retained its structure even though it is dispersed in polymer matrix during synthesis reaction.

The TGA curve of PANI, ZnO and PANI@ZnO were showed in Fig. 1-d. PANI displayed the initial weight loss $(10.21 \%)$ below $266^{\circ} \mathrm{C}$, which was attributed to the loss of $\mathrm{H}_{2} \mathrm{O}$ and solvents molecules. The second weight loss $(42.51 \%)$ in the range from $266^{\circ} \mathrm{C}$ to 447 ${ }^{\circ} \mathrm{C}$ was due to the removal of structural organic ligands from their frameworks. At $900{ }^{\circ} \mathrm{C}$, the total weight loss of PANI was $66.21 \%$, while PANI@ZnO was 50.51\%. The reason is that the presence of PANI on the surface of $\mathrm{ZnO}$ promoted the growth of the crystal. It was concluded that PANI@ZnO had better thermal stability than polymer, mainly due to the introduction of $\mathrm{ZnO}$ in PANI matrix.

The SEM images of samples are shown in Fig. 2. The $\mathrm{ZnO}$ nanoparticles were grain and it has the shape of faceted crystals [39]. This material is characterized by adequate porosity. While, PANI shows a classically cauliflower-like morphology [40]. Whereas that, the SEM images clearly exhibit the dual structure of PANI@ZnO hybrid that is comprised of spherical particles are surrounded by polymer matrix and hence it appears as agglomerated macromolecules [41]. 

adsorption-desorption isotherms determined and the obtained values is described in Table 2 and Fig. 3-a. It is found that the measurement $\mathrm{S}_{\text {BET }}$ of PANI@ZnO was increased in some extent due to existence of $\mathrm{ZnO}$ nanoparticles, indicating large ratio of macropores in hybrid adsorbent. The textural characteristic of PANI@ZnO is more favorable to the adsorption of dyes [42].

\subsection{Adsorption of $M O$}

\subsubsection{Influence of $\mathrm{pH}$}

The effect the $\mathrm{pH}$ solution has on the dyes (CR or $\mathrm{MB}$ ) removal was investigated by modifying the reaction solution $\mathrm{pH}$ from 4 to 11 and conserving all other parameters constant by PANI@ZnO adsorbent. Herein, lower pHs were not tested due to the instability of CR below $\mathrm{pH} 5$ [43]. Fig. 3-b shows the effect $\mathrm{pH}$ has on removal efficiency. It is clear that PANI@ZnO performed better in the adsorption of CR from aqueous solution at various values of $\mathrm{pH}$ compared with $\mathrm{MB}$ dye. As observed, the adsorbent hybrid has a high potential for both dyes removal on the $\mathrm{pH}$ between 5 and 6. Furthermore, as Emeraldine-Salt (ES) and Emeraldine-Base (EB) formulas of the PANI in adsorbent hybrid occur at lower acidic and higher basic $\mathrm{pH}$ values respectively, the ES form get passed to $\mathrm{EB}$ about $\mathrm{pH} 7$ [44]. Accordingly, the decrease in the dyes removal efficiency is may be related to this phenomenon that the surface of the PANI@ZnO adsorbent becomes less positive when pH increased from 5 to 11 . The negative charge on the surface of adsorbents promotes repelling of negatively charged dyes. Therefore, $\mathrm{pH} 5$ was selected for further experiments.

\subsubsection{Effect of adsorption time on adsorption efficiency}


Fig. 3-c. exhibits a comparison of the $\mathrm{CR}$ and $\mathrm{MB}$ dyes adsorption capacity by PANI@ZnO adsorbent and removal efficiency with time. The results displayed that the \%removal of CR increased with increasing time from 10 to 40 min where reached $19.23 \%$ at 40 min. Thereafter, the \%removal of CR increased to $81.37 \%$ when the time changed from 40 to $60 \mathrm{~min}$. Also, the influence of time on the adsorption capacity of PANI@ZnO adsorbent toward $\mathrm{MB}$ was performed in the time range of 10-120 min. The results also showed that the adsorption capacity toward $\mathrm{MB}$ increased with increasing time from 10 to $60 \mathrm{~min}$ where reached $59.23 \mathrm{mg} \cdot \mathrm{g}^{-1}(76.48 \%)$ at $60 \mathrm{~min}$. Hence, longer times had no significant effect on the results which revealed a relatively fast adsorption process. Based on the obtained results, a time of $60 \mathrm{~min}$ was selected as the equilibrium time for further experiments.

To prepare information about factors affecting reaction rate, it is necessary to determine mechanisms that control the adsorption process such as surface adsorption, chemical reaction, and kinetics assessment infiltration mechanisms. PFO and PSO models have widely used for investigation of the adsorption process. In Table 3, the parameters related to studied kinetic models are presented. Accordingly, the PSO kinetic model provided the best results regarding $R^{2}$ value which proposes a physiochemical adsorption process and an intraparticle diffusion mechanism for both dyes. The obtained $R^{2}$ values for PSO model were 0.977 and 0.991 for CR and MB dyes, respectively. Also, the calculated value of $Q_{\text {eq.Cal }}$ obtained from the PSO model is close to the experimental value of $Q_{\text {eq.Exp }}$. Hence, the kinetics of adsorption is best defined by the PSO kinetic model for both dyes used in this study.

\subsection{Adsorption isotherms of dyes}


Fig. 3-d. displays the adsorption isotherms of both dyes (CR or MB) by PANI@ZnO nanoadsorbent calculated at $298 \mathrm{~K}$. The matching result of sorption isotherms using Langmuir and Freundlich models are summarized in Table 4. The data show that the removal process of dyes was fitted well with the Langmuir isotherm. Likewise, this isotherm model indicates heterogeneous and multilayer adsorption sites. Further, the removal capacity toward CR and MB by PANI@ZnO are $69.82 \mathrm{mg} . \mathrm{g}^{-1}$ and $56.23 \mathrm{mg} . \mathrm{g}^{-1}$, respectively. To compare the present method with other reported studies for the adsorption of CR or MB, adsorption capacity of the methods is summarized in Table 5. Thus, the present study provided better adsorption capacity in comparison with other reported methods using adsorbent. One possible reason for the better performance of the prepared adsorbents is the adsorption mechanism, which occurs in both anion exchange and surface adsorption by H-bonding with $\pi-\pi$ liaison.

\subsection{Reuse of adsorbent}

Regeneration and reusability of an adsorbent material is an important factor to assess the feasibility for workable applications. Therefore, this adsorbent product was used for several adsorption-regeneration cycles with removal over $60 \mathrm{~min}$. In this study, washing of employed adsorbent with $\mathrm{C}_{2} \mathrm{H}_{5} \mathrm{OH}$ and distilled $\mathrm{H}_{2} \mathrm{O}$ was used to regenerate the adsorbent PANI@ $\mathrm{ZnO}$. As shown in Fig. 4. the adsorbent present suitable capabilities for recovery and reuse. Besides, the adsorbent recovery at some steps showed a stable adsorbent capacity in dye removal which this result can illustrate that $\mathrm{C}_{2} \mathrm{H}_{5} \mathrm{OH}$ is an exceptional detergent for adsorbent recovery. On the other hand, the continuous decrease in quantity adsorbed and reusability efficiency could suggest that some dyes remained on adsorbent material next each reusability or that the adsorbent structure was changing. 


\section{Conclusions}

In this research, PANI@ZnO nanocomposite was facilely prepared by in-situ oxidative polymerization. After the characterization of the synthesized nanocomposite by XPS, XRD, FTIR, TGA, SEM and BET analyses, this hybrid material were applied as novel adsorbent for removal of $\mathrm{CR}$ and $\mathrm{MB}$ dyes from aqueous solution. The effect of important experimental parameters including solution $\mathrm{pH}$, contact time, dyes concentration, kinetics, and isothermal analysis was investigated. The novel prepared nanoadsorbent showed significant adsorption performance toward both dyes. Moreover, the kinetic analysis detected that PSO rate formula executed better than PFO rate law, this promoting the formation of physiochemical adsorption process and an intraparticle diffusion mechanism. For isothermal studies, the Freundlich model showed the best fit based on $R^{2}$ values. Finally, maximum adsorption capacities of 69.82 mg.g ${ }^{-1}$ and 59.23 mg. $\mathrm{g}^{-1}$ were obtained for CR and MB dyes, respectively, by PANI@ZnO adsorption. Additionally, the obtained nanoadsorbent exhibited an adequate cyclability to a range between $77.14 \%$ and $40.34 \%$ after 5 cycles.

\section{Acknowledgements}

Authors gratefully acknowledge the Algerian Ministry of Higher Education and

Scientific Research, and also University Materials Science Institute of Alicante Spain for the co-operation availing.

Funding information: There is no financial sources funding regarding of this study. 


\section{References}

300

301

302

303

304

305

306

307

308

309

310

[1] R. Pandimurugan, S. Thambidurai. Synthesis of seaweed-ZnO-PANI hybrid composite for adsorption of methylene blue dye. Journal of Environmental Chemical Engineering. 4 (2016) 1332-1347.

[2] D.S. Brookstein. Factors Associated with textile pattern dermatitis caused by contact allergy to dyes finishes, foam and preservatives. Dermatologic Clinics. 27 (2009) 309-322

[3] P.A. Carneiro, G.A. Umbuzeiro, D.P. Oliveira, M.V.B. Zanoni. Assessment of water contamination caused by a mutagenic textile effluent/dye house effluent bearing disperse dyes. Journal of Hazardous Materials. 174 (2010) 694-699.

[4] P. Mokhtari, M. Ghaedi, K. Dashtian, M.R. Rahimi, M.K. Purkait. Removal of methyl orange by copper sulfide nanoparticles loaded activated carbon: Kinetic and isotherm investigation. Journal of Molecular Liquids. 219 (2016) 299-305.

[5] B.A.M. Al-Rashdi, D.J. Johnson, N. Hilal. Removal of heavy metal ions by nanofiltration. Desalination, 315 (2013) 2-17.

[6] S. Dashamiri, M. Ghaedi, K. Dashtian, M.R. Rahimi, A. Goudarzi, R. Jannesar. Ultrasonic enhancement of the simultaneous removal of quaternary toxic organic dyes by $\mathrm{CuO}$ nanoparticles loaded on activated carbon: Central composite design, kinetic and isotherm study. Ultrasonics Sonochemistry. 31 (2016) 546-557.

[7] A. Paz, J. Carballo, M.J. Perez, J.M. Dominguez. Biological treatment of model dyes and textile wastewater. Chemosphere. 181 (2017) 168-177 
[8] S. Sachdeva, A. Kumar. Preparation of nanoporous composite carbon membrane for separation of rhodamine B dye. Journal of Membrane Science. 329 (2009) 2-10.

[9] A. Asfaram, M. Ghaedi, S Hajati, A. Goudarzi, A.A. Bazrafshan. Simultaneous ultrasoundassisted ternary adsorption of dyes onto copper-doped zinc sulfide nanoparticles loaded on activated carbon: Optimization by response surface methodology. Spectrochimica Acta Part A: Molecular and Biomolecular Spectroscopy. 145 (2015) 203-212.

[10] K. Dai, H. Chen, T. Peng, D. Ke, H. Yi. Photocatalytic degradation of methyl orange in aqueous suspension of mesoporous titania nanoparticles. Chemosphere. 69 (2007) 13611367.

[11] A. Asfaram, M. Ghaedi, S. Hajati, M. Rezaeinejad, A. Goudarzi, M.K. Purkait. Rapid removal of Auramine-O and Methylene blue by $\mathrm{ZnS}: \mathrm{Cu}$ nanoparticles loaded on activated carbon: A response surface methodology approach. Journal of the Taiwan Institute of Chemical Engineers. 53 (2015) 80-91.

[12] G. Crini. Non-conventional low-cost adsorbents for dye removal: a review. Bioresour. Technol., 97 (2006) 1061-1085.

[13] H. Wu, S. Lin, C. Chen, W. Liang, X. Liu, H. Yang.A new ZnO/rGO/polyaniline ternary nanocomposite as photocatalyst with improved photocatalytic activity.Materials Research Bulletin. 83 (2016) 434-441.

[14] C. Chen, T. Xu, A. Chen, L. Lu, Y. Gao. Electrosynthesis of poly(Nmethylthionine)/polyaniline nanocomposites with enhanced electrochemical and electrocatalytic activities. Journal of the Electrochemical Society. 163 (2016) G159-G165 
[15] A. Eftekhari. Nanostructured Conductive Polymers. John Wiley \& Sons (2011).

[16] X. Zheng, M.E.A. Mohsin, A. Arsad, A. Hassan. Polymerization of polyaniline under various concentrations of ammonium peroxydisulfate and hydrochloric acid by ultrasonic irradiation. Journal of Applied Polymer Science. 138 (2021) 50637.

[17] S. Daikh, F. Z. Zeggai, A. Bellil, A. Benyoucef. Chemical polymerization, characterization and electrochemical studies of PANI/ZnO doped with hydrochloric acid and/or zinc chloride: Differences between the synthesized nanocomposites. Journal of Physics and Chemistry of Solids. 121 (2018) 78-84.

[18] M. Zhang, A. Nautiyal, H. Du, Z. Wei, X. Zhang, R. Wang. Electropolymerization of polyaniline as high-performance binder free electrodes for flexible supercapacitor. Electrochimica Acta. 376 (2021) 138037.

[19] D.S. Torres, F. Montilla, F. Huerta, E. Morallón. All electrochemical synthesis of polyaniline/silica sol-gel materials. Electrochimica Acta. 56 (2011) 3620-3625.

[20] L. Maaza, F. Djafri, A. Belmokhtar, A. Benyoucef. Evaluation of the influence of Al2O3 nanoparticles on the thermal stability and optical and electrochemical properties of PANIderived matrix reinforced conducting polymer composites. Journal of Physics and Chemistry of Solids. 152 (2021) 109970.

[21] M.A. Bekhti, M.S. Belardja, M. Lafjah, F. Chouli, A. Benyoucef. Enhanced tailored of thermal stability, optical and electrochemical properties of PANI matrix containing $\mathrm{Al}_{2} \mathrm{O}_{3}$ hybrid materials synthesized through in situ polymerization. Polymer Composites. 42 (2021) 6-14. 
[22] M.S. Belardja, H. Djelad, M. Lafjah, F. Chouli, A. Benyoucef. "The influence of the addition of tungsten trioxide nanoparticle size on structure, thermal, and electroactivity properties of hybrid material-reinforced PANI". Colloid and Polymer Science. 298 (2020) 1455-1463.

[23] I. Litty, V.P.N. Nampoori, P. Radhakrishnan. Optical Limiting in ZnO Nanocomposites. Science of Advanced Materials. 2 (2010) 578-582.

[24] L. Hongjun, Z. Zang, X. Tang. Synthesis mechanism and optical properties of well nanoflower-shaped $\mathrm{ZnO}$ fabricated by a facile method. Optical Materials Express. 4 (2014) 1762-1769.

[25] O. Mahi, K. Khaldi, M. S. Belardja, A. Belmokhtar, A. Benyoucef. Development of a New Hybrid Adsorbent from Opuntia Ficus Indica NaOH Activated with PANI Reinforced and Its Potential Use in Orange G Dye Removal. Journal of Inorganic and Organometallic Polymers and Materials. 31 (2021) 2095-2104.

[26] R. Saravanan, E. Sacari, F. Gracia, M.M. Khan, E. Mosquera, V.K. Gupta. Conducting PANI stimulated $\mathrm{ZnO}$ system for visible light photocatalytic degradation of coloured dyes. Journal of Molecular Liquids. 221 (2016) 1029-1033.

[27] V. Eskizeybek, F. Sarı, H. Gülce, A. Gülce, A. Avcı. Preparation of the new polyaniline/ZnO nanocomposite and its photocatalytic activity for degradation of methylene blue and malachite green dyes under UV and natural sun light irradiations. Applied Catalysis B: Environmental. 119-120 (2012) 197-206 
[28] R. Kumar, S.A. Ansari, M.A. Barakat, A. Aljaafari, M.H. Cho. A polyaniline@MoS2based organic-inorganic nanohybrid for the removal of Congo red: adsorption kinetic, thermodynamic and isotherm studies. New Journal of Chemistry. 40 (2018) 18802-18809

[29] R. Ahmad, R. Kumar. Conducting Polyaniline/Iron Oxide Composite: A Novel Adsorbent for the Removal of Amido Black 10B. Journal of Chemical \& Engineering Data. 55 (2010) 3489-3493.

[30] F. Z. Kouidri, I. Moulefera, S. Bahoussi, A. Belmokhtar, A. Benyoucef. Development of hybrid materials based on carbon black reinforced poly(2-methoxyaniline): preparation, characterization and tailoring optical, thermal and electrochemical properties. Colloid and Polymer Science (2021). doi.org/10.1007/s00396-021-04837-2.

[31] A. Belalia, A. Zehhaf, A. Benyoucef. Preparation of Hybrid Material Based of PANI with $\mathrm{SiO}_{2}$ and Its Adsorption of Phenol from Aqueous Solution. Polymer Science, Series B. 60 (2018) 816-824.

[32] M. Zenasni, A.Q. Jaime, A. Benyoucef, A. Benghalem. Synthesis and characterization of polymer/ $/ \mathrm{V}_{2} \mathrm{O}_{5}$ composites based on poly(2-aminodiphenylamine). Polymer Composites. 42 (2021) 1064-1074.

[33] M.H. Sadeghi, M.A. Tofighy, T. Mohammadi. One-dimensional graphene for efficient aqueous heavy metal adsorption: Rapid removal of arsenic and mercury ions by graphene oxide nanoribbons (GONRs). Chemosphere. 253 (2020) 126647. 
[34] A.B. Wozniak, R. Pietrzak. Adsorption of organic and inorganic pollutants on activated bio-carbons prepared by chemical activation of residues of supercritical extraction of raw plants. Chemical Engineering Journal. 393 (2020) 124785.

[35] R.R. Amador, J. Alvarado, G.F. Carrasco, L.M. de la Garza, S.A. Iniesta, A.L. Flores, Y.P. Bernal, M.A.M. Rojas, J.J.G. Arciniega, H.P.M. Hernández, J.F.C. Vega, J.B. Camacho. The Influence of Deposition Time on the Structural, Morphological, Optical and Electrical Properties of ZnO-rGO Nanocomposite Thin Films Grown in a Single Step by USP. Crystals. 10 (2020) 1-21.

[36] M. Javed, S.M. Abbas, M. Siddiq, D. Han, L. Niu, Mesoporous silica wrapped with graphene oxide-conducting PANI nanowires as a novel hybrid electrode for supercapacitor. Journal of Physics and Chemistry of Solids. 113 (2018) 220-228.

[37] L. Wu, Y. Wu, X. Pan, F. Kong. Synthesis of $\mathrm{ZnO}$ nanorod and the annealing effect on its photoluminescence property. Optical Materials. 28 (2006) 418-422.

[38] Z. Yang, Q. H. Liu. The structural and optical properties of $\mathrm{ZnO}$ nanorods via citric acidassisted annealing route. Journal of Materials Science. 43 (2008) 6527-6530.

[39] W. Bai, Z. Zhang, W. Tian, X. He, Y. Ma, Y. Zhao, Z. Chai. Toxicity of zinc oxide nanoparticles to zebrafish embryo: a physicochemical study of toxicity mechanism. Journal of Nanoparticle Research. 12 (2010) 1645-1654.

[40] S. Matindoust, A. Farzi, M.B. Nejad, M.H.S. Abadi, Z. Zou, L.R. Zheng. Ammonia gas sensor based on flexible polyaniline films for rapid detection of spoilage in protein-rich foods. Journal of Materials Science: Materials in Electronics. 28 (2017) 7760-7768. 
421 [41] V. Gilja, I. Vrban, V. Mandić, M. Žic, Z.H. Murgić. Preparation of a PANI/ZnO Composite for Efficient Photocatalytic Degradation of Acid Blue. Polymers. 10 (2018) 117.

[42] C. Bao, M. Chen, X. Jin, D. Hu, Q. Huang. Efficient and stable photocatalytic reduction of aqueous hexavalent chromium ions by polyaniline surface-hybridized $\mathrm{ZnO}$ nanosheets. Journal of Molecular Liquids. 279 (2019) 133-145.

[43] G. Sriram, U. Uthappa, D. Losic, M. Kigga, H.Y. Jung, M.D. Kurkuri. Mg-Al-Layered Double Hydroxide (LDH) Modified Diatoms for Highly Efficient Removal of Congo Red from Aqueous Solution. Applied Sciences. 10 (2020) 2285.

[44] T. Lindfors, A. Ivaska. $\mathrm{pH}$ sensitivity of polyaniline and its substituted derivatives. Journal of Electroanalytical Chemistry. 531 (2002) 43-52.

[45] H. Zhang, J. Ma, F. Wang, Y. Chu, L. Yang, M. Xia. Mechanism of carboxymethyl chitosan hybrid montmorillonite and adsorption of $\mathrm{Pb}(\mathrm{II})$ and Congo red by CMC-MMT organic-inorganic hybrid composite. International Journal of Biological Macromolecules. 149 (2020) 1161-1169.

[46] A.O. Adesina, O.A. Elvis, N.D.S. Mohallem, S.J. Olusegun. Adsorption of Methylene blue and Congo red from aqueous solution using synthesized alumina-zirconia composite. Environmental Technology . 42 (2021) 1061-1070.

[47] C.M. Simonescu, A. Tătăruş, D.C. Culiţă, N. Stănică, I.A. Ionescu, B. Butoi, A.M. Banici. Comparative Study of CoFe2O4 Nanoparticles and CoFe2O4-Chitosan Composite for Congo Red and Methyl Orange Removal by Adsorption. Nanomaterials. 11 (2021) 1-24. 
[48] R. Wo, Q.L. Li, C. Zhu, Y. Zhang, G.F. Qiao, K.Y. Lei, P. Du, W. Jiang. Preparation and Characterization of Functionalized Metal-Organic Frameworks with Core/Shell Magnetic Particles (Fe3O4@SiO2@MOFs) for Removal of Congo Red and Methylene Blue from Water Solution. Journal of Chemical \& Engineering Data. 64 (2019) 2455-2463.

[49] C. Aoopngan, J. Nonkumwong, S. Phumying, W. Promjantuek, S. Maensiri, P. Noisa, S. Pinitsoontorn, S. Ananta, L. Srisombat. Amine-Functionalized and HydroxylFunctionalized Magnesium Ferrite Nanoparticles for Congo Red Adsorption. ACS Applied Nano Materials. 2 (2019) 5329-5341.

[50] H. Chafai, M. Laabd, S. Elbariji, M. Bazzaoui, A. Albourine. Study of congo red adsorption on the polyaniline and polypyrrole. Journal of Dispersion Science and Technology. 38 (2017) 832-836.

[51] M.O. Ansari, R. Kumar, S.A. Ansari, S.P. Ansari, M.A. Barakat, A. Alshahrie, M.H. Cho. Anion selective pTSA doped polyaniline@graphene oxide-multiwalled carbon nanotube composite for $\mathrm{Cr}(\mathrm{VI})$ and Congo red adsorption. Journal of Colloid and Interface Science. 496 (2017) 407-415.

[52] R. Kumar, M.O. Ansari, N. Parveen, M.A. Barakat, M.H. Cho. Simple route for the generation of differently functionalized PVC@graphene-polyaniline fiber bundles for the removal of Congo red from wastewater. RSC Adv., 5 (2015) 61486-61494.

[53] S. Singh, S. Perween, A. Ranjan. Dramatic enhancement in adsorption of congo red dye in polymer-nanoparticle composite of polyaniline-zinc titanate. Journal of Environmental Chemical Engineering. 9 (2021) 105149 
[54] S. Dhananasekaran, R. Palanivel, S. Pappu. Adsorption of Methylene blue, bromophenol blue, and coomassie brilliant blue by $\alpha$-chitin nanoparticles. Journal of Advanced Research. 7 (2016) 113-124.

[55] D.S. Franco, E.H. Tanabe, D.A. Bertuol, G.S. Dos Reis, E.C. Lima, G.L. Dotto. Alternative treatments to improve the potential of rice husk as adsorbent for methylene blue. Water Sci Technol, 75 (2017) 296-305.

[56] M.O. Bello, N. Abdus-Salam, F.A. Adekola, U. Pal. Isotherm and kinetic studies of adsorption of methylene blue using activated carbon from ackee apple pods. Chemical Data Collections. 31 (2021) 100607

[57] R. Jamal, L. Zhang, M. Wang, Q. Zhao, T. Abdiryim. Synthesis of poly(3,4propylenedioxythiophene)/MnO2 composites and their applications in the adsorptive removal of methylene blue. Progress in Natural Science: Materials International. 26 (2016) 32-40.

[58] M.M. Ayad, A.A. EI-Nasr. Adsorption of cationic dye (Methylene Blue) from water using polyaniline nanotubes base. Journal of Physical Chemistry C.114 (2010) 14377-14383.

[59] M. Ayad, S. Zaghlol. Nanostructured crosslinked polyaniline with high surface area: synthesis characterization and adsorption for organic dye. Chemical Engineering Journal. 204-206 (2012) 79-86. 


\section{Captions}

484 Fig. 1. (a) : Survey XPS spectra ; (b) : FTIR adsorption spectra ; (c) : XRD patterns and (d) : 485 Thermogravimetric analysis obtained in $\mathrm{N}_{2}$ atmosphere at $10^{\circ} \mathrm{C} \cdot \mathrm{min}^{-1}$ of $\mathrm{ZnO}$, PANI and 486 PANI@ZnO.

487 Fig. 2. SEM images of materials synthetized: (a) ZnO ; (b) PANI and (c) PANI@ZnO.

Fig. 3. (a) : $\mathrm{N}_{2}$ adsorption \& desorption isotherm of adsorbents materials fabricated ; (b) : 489 Effect of pHs on the adsorption capacity of dyes by PANI@ZnO materials (adsorbent dose: 10 $490 \mathrm{mg}$; dye (CR or MB): $25 \mathrm{~mL} ; \mathrm{T}: 298 \mathrm{~K})$; (c): Contact Time $\left(\mathrm{C}_{0}: 150 \mathrm{mg} . \mathrm{L}^{-1}\right.$; pH: 5.0; T: 298K; 491 adsorbents dose: $10 \mathrm{mg}$ ) ; (d): Adsorption isotherms of dyes by nanomaterial (adsorbent dose: $49210 \mathrm{mg}$; dye (CR or MB): $25 \mathrm{~mL}$; T: $298 \mathrm{~K}$; pH: 5.0).

493 Fig. 4. Adsorbent capacity changes and initial dyes (CR and $M B)$ in consecutive cycles 494 (adsorbent dose: $10 \mathrm{mg}$; dye (CR or MB): $25 \mathrm{~mL}$; T: $298 \mathrm{~K}$; pH: 5.0). 
Figures

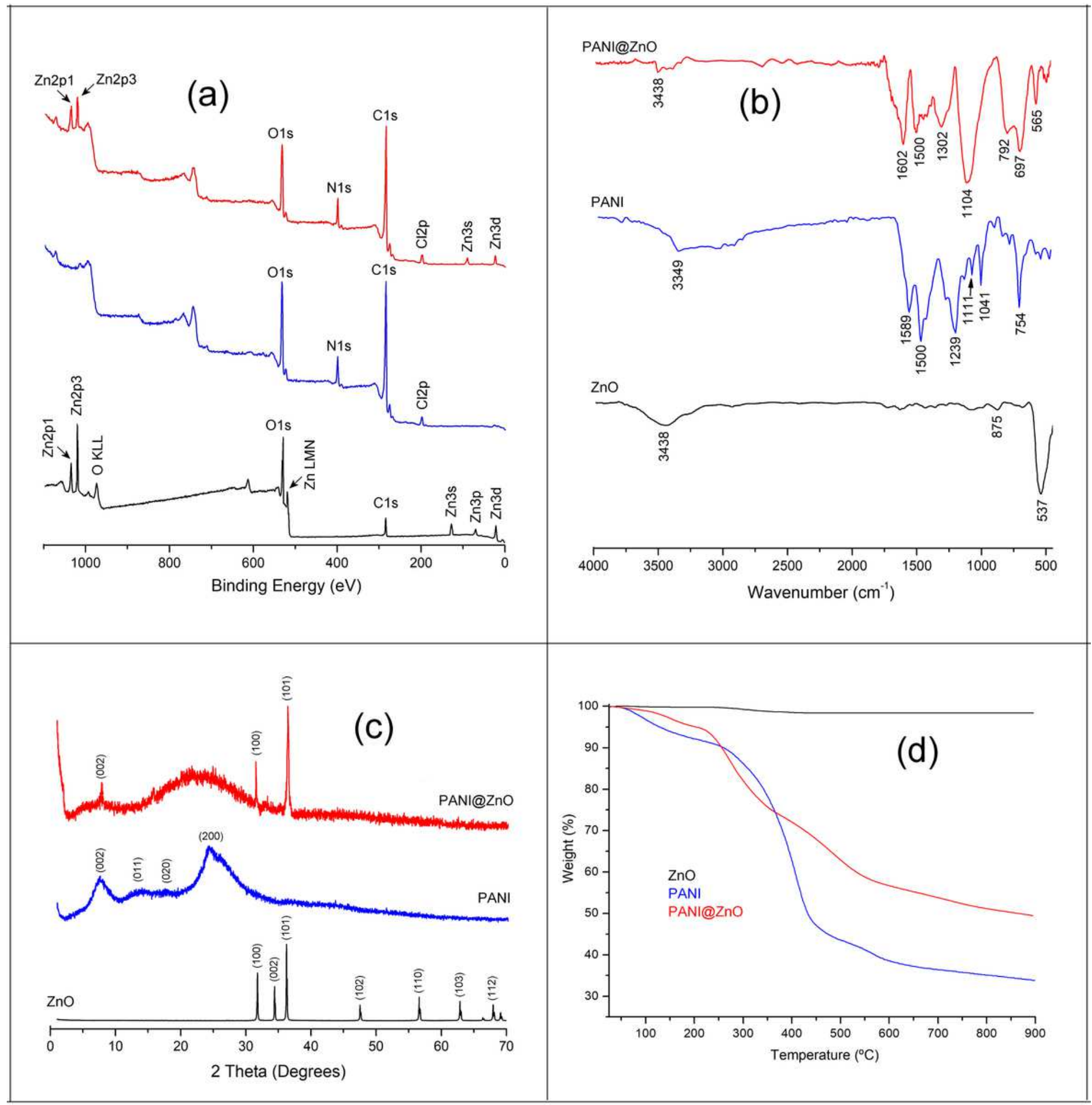

Figure 1

(a) : Survey XPS spectra ; (b) : FTIR adsorption spectra ; (c) : XRD patterns and (d) : Thermogravimetric analysis obtained in $\mathrm{N} 2$ atmosphere at $10^{\circ} \mathrm{C} . \mathrm{min}-1$ of ZnO, PANI and PANI@ZnO. 

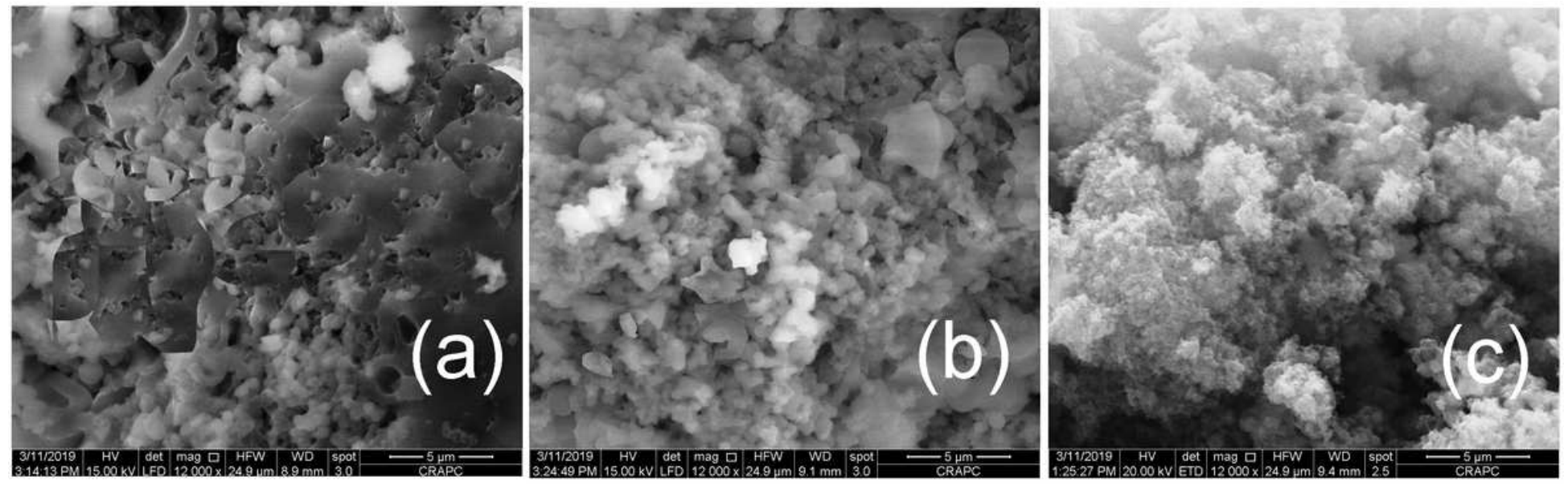

Figure 2

SEM images of materials synthetized: (a) ZnO ; (b) PANI and (c) PANI@ZnO.

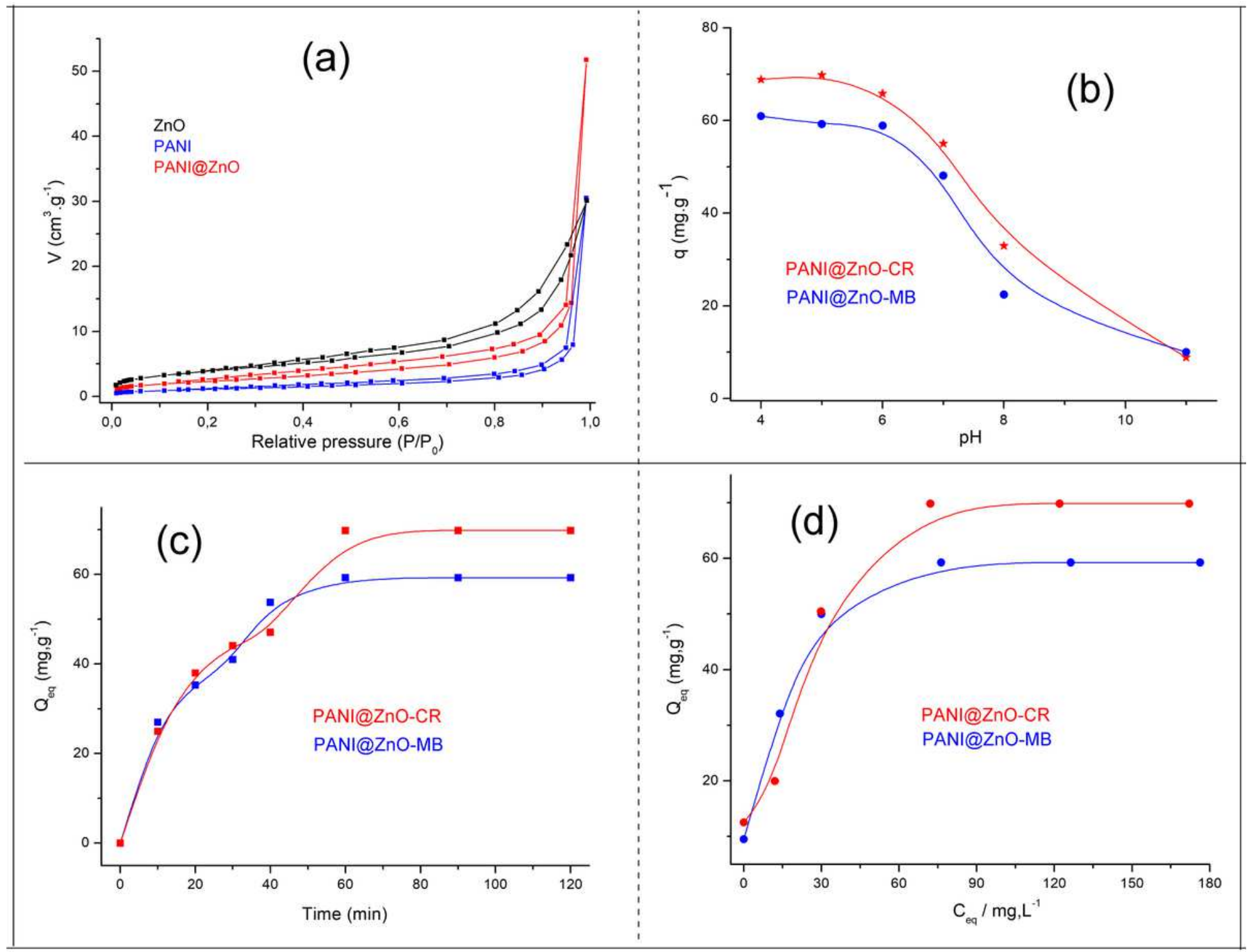

Figure 3 
(a) : N2 adsorption \& desorption isotherm of adsorbents materials fabricated ; (b) : Effect of pHs on the adsorption capacity of dyes by PANI@ZnO materials (adsorbent dose: 10 mg; dye (CR or MB): $25 \mathrm{~mL} ; \mathrm{T}$ : 298 K) ; (c): Contact Time (C0: 150 mg.L-1; pH: 5.0; T: 298K; adsorbents dose: 10 mg) ; (d): Adsorption isotherms of dyes by nanomaterial (adsorbent dose: $10 \mathrm{mg}$; dye (CR or MB): $25 \mathrm{~mL} ; \mathrm{T}: 298 \mathrm{~K} ; \mathrm{pH}: 5.0$ ).

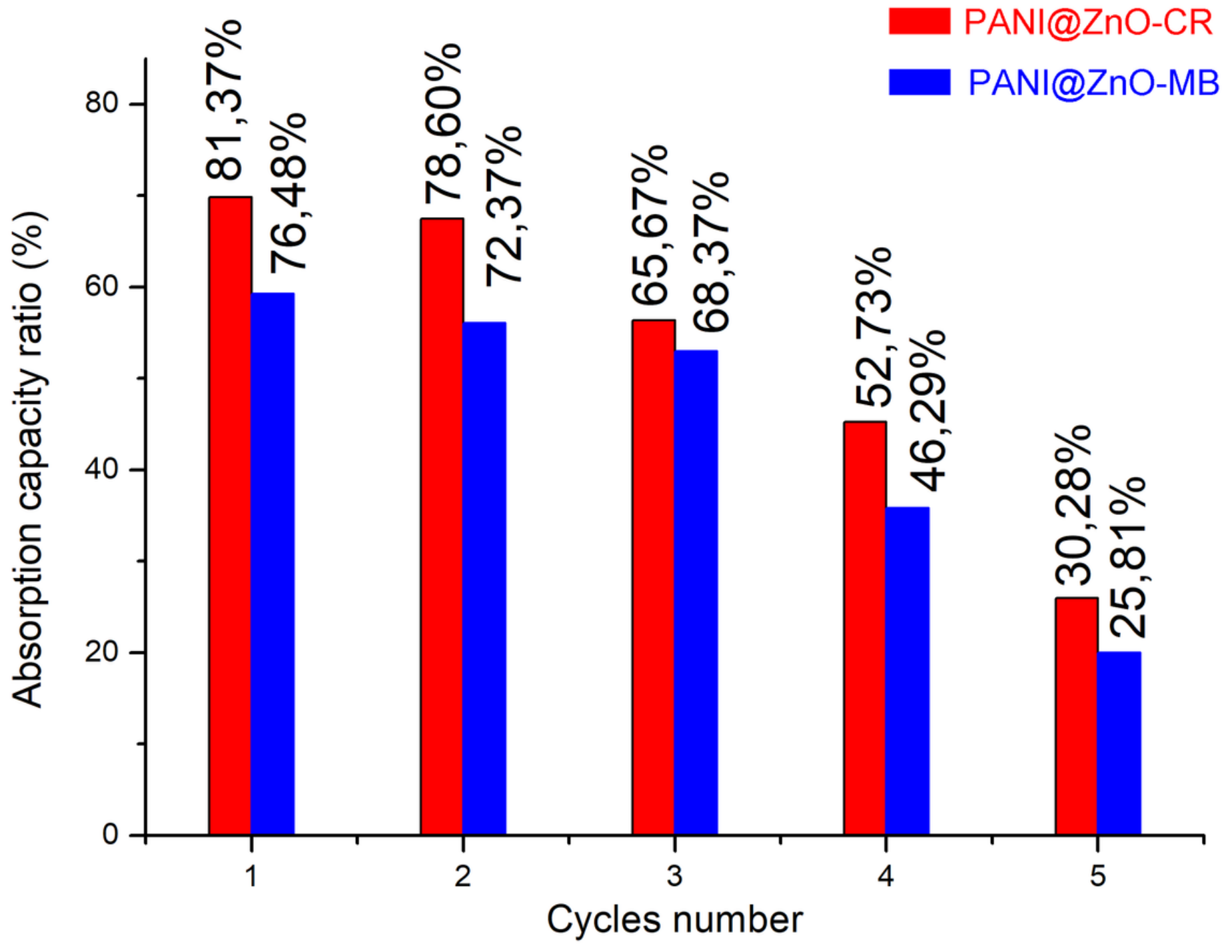

Figure 4

Adsorbent capacity changes and initial dyes (CR and MB) in consecutive cycles (adsorbent dose: $10 \mathrm{mg}$; dye (CR or MB): 25 mL; T: 298 K; pH: 5.0). 